\title{
Predictive value of a 24 hour tuberculin skin test evaluation
}

Fadıl Öztürk, Muzaffer Eskiocak, Ali Bay, Recep Sancak, Şennur Dabak, Nuran Gürses

\begin{abstract}
The predictive value of induration 24 hours after administration of purified protein derivative (PPD) was examined. Altogether 1082 healthy schoolchildren were tested using 5 tuberculin units of PPD. Induration was measured at 24,48 , and 72 hours. At 24 hours, induration of any size had a relatively low positive predictive value $(63 \%)$, although indurations $>5 \mathrm{~mm}$ had a higher $(86 \%)$ positive predictive value.

(Arch Dis Child 1997;76:452-453)
\end{abstract}

Keywords: tuberculin test; predictive value

In Turkey, overall prevalence of tuberculosis is $3.58 / 1000$ and the prevalence of tuberculous infection (tuberculin positive cases with no BCG vaccine) among the paediatric age groups varies from 6.9 to $32 \%$. With a prevalence of $4.58 / 1000$ the Black Sea region, which includes Samsun, has one of the highest adult and childhood tuberculosis rates in Turkey. ${ }^{1}$

Rapid diagnosis and early medical intervention is essential to prevent widespread disease. The tuberculin skin test is the only method for detecting Mycobacterium tuberculosis infection. In most cases, a positive test signifies infection with $M$ tuberculosis and allows treatment of the asymptomatic patient before symptomatic tuberculosis develops. ${ }^{2}{ }^{3}$

The test reveals a person's delayed type local hypersensitivity to $M$ tuberculosis. According to current recommendations only indurations read 48 to 72 hours after the test are valid. ${ }^{2}$ However, Howard and Solomon showed that in adults the size of induration at 24 hours was highly predictive of eventual findings at 48 to 72 hours. $^{4}$

In this study we aimed to determine the value of the induration 24 hours after placement of purified protein derivative (PPD) in children.

Directorate of Mother and Child Health, and Family Planning,

Samsun, Turkey

M Eskiocak

Ondokuz Mayis University School of Medicine, Department of Public Health, Samsun, Turkey Ş Dabak

Correspondence to: Dr Öztürk.

Accepted 26 November 1996 in the previous five years, and none had a condition known to cause anergy. A 5 tuberculin unit dose of PPD (Tuberculin PPD, InterVax
Biologicals Limited, Canada, Serial No 3850196) was administered by a single experienced nurse using the Mantoux technique. Twenty four hours after placement of the skin test, the maximum transverse diameter of induration was measured with a transparent plastic ruler by two of the authors. Each of the readers independently measured the induration in each subject by palpation technique. At 48 and 72 hours, second and third measurements were done by the same readers. The readers were blinded during all the three readings. Twenty one of 1082 children were excluded from the study because of failure to return for assessment.

Statistical analysis was performed using the two tailed paired Student's $t$ test. Sensitivity, specificity, and predictive values were calculated for the indurations at 24 hours.

\section{Results}

There were no differences between the readers' ability to measure the size of the induration independently $(p>0.5)$. No individual reading differed by $>2 \mathrm{~mm}$ between the two readers.

Of the 1061 children included in the study, 168 did not have BCG scars, 660 had one scar, and 233 had two or more scars. Tuberculin indurations $\geqslant 10 \mathrm{~mm}$ were found respectively in $11.9 \%, 25.1 \%$, and $62.6 \%$ of the children with no scar, with one scar, and with two or more scars. The mean (SD) size of the induration at 24 hours was less than that of the induration present at 48 and 72 hours (3.9(5.6), $5.2(6.4)$, and $5.3(6.4) \mathrm{mm}$, respectively). Differences were statistically significant $(p<0.0001)$. There was no difference between 48 and 72 hours readings $(p>0.5)$. Table 1 shows the amount of induration at 24 hours and its relationship to subsequent outcome at 72 hours. The distribution of reaction sizes at various readings is shown in fig 1 . Induration $\geqslant 10 \mathrm{~mm}$ at 72 hours was considered to be positive; induration $<10 \mathrm{~mm}$ at 72 hours was defined negative. With 332 positive skin tests in our study population tuberculin positivity was $31.3 \%$. Of these, 311 had induration noted at 24 hours. Of the 729 subjects with $<10 \mathrm{~mm}$ induration at 72 hours, 545 subjects had no induration noted at 24 hours. Therefore, any induration 24 hours after placement of the tuberculin PPD test has a sensitivity of $94 \%$ and a specificity of $75 \%$. Of the 495 subjects with any induration at 24 hours, 311 had positive tests at 72 hours, giving a positive predictive value of $63 \%$. This value reached $86 \%$ if the size of induration at 24 hours was $\geqslant 5 \mathrm{~mm}$. Of the 566 subjects without indura- 
Table 1 Relationship of 24 hour readings to results at 72 hours

\begin{tabular}{lcc}
\hline $\begin{array}{l}\text { Induration at } 24 \\
\text { hours }(\mathrm{mm})\end{array}$ & $\begin{array}{l}\text { No of subjects } \geqslant 10 \\
\text { mm at } 72 \text { hours }\end{array}$ & $\begin{array}{l}\text { No of subjects }<10 \\
\text { mm at } 72 \text { hours }\end{array}$ \\
\hline 0 & 21 & 545 \\
$1-4$ & 27 & 137 \\
$5-9$ & 101 & 46 \\
$10-14$ & 112 & 1 \\
$15-19$ & 53 & 1 \\
$20-24$ & 16 & 0 \\
$\geqslant 25$ & 2 & 0
\end{tabular}

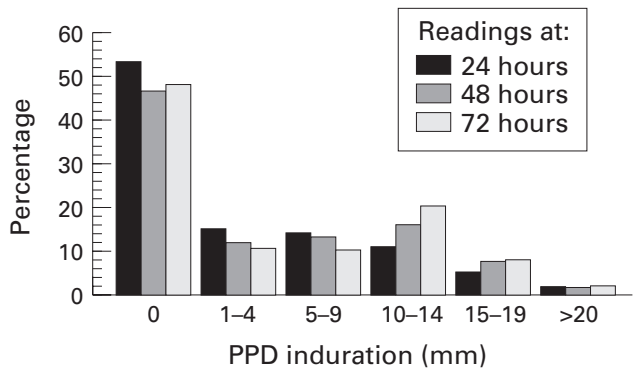

Figure 1 Distribution of reaction sizes at the three readings.

tion at 24 hours, 545 were truly negative at 72 hours resulting in a negative predictive value of $96 \%$.

The positive predictive value of any induration at 24 hours was found to be $51 \%$ for children aged $6-7$ years, $57 \%$ for children aged 11-12 years, and $80 \%$ for children aged 16-17 years. The negative predictive value of no induration at 24 hours was $98 \%$ for children aged 6-7 and 11-12 years, and $87 \%$ for children aged $16-17$ years.

\section{Discussion}

We found that $332 / 1061$ (31.3\%) of the normal healthy school aged children tested had $\geqslant 10$ $\mathrm{mm}$ induration at 72 hours. In 1995, a study of 3548 children from elementary schools in a city in the Marmara Region of Turkey showed that $29.8 \%$ had an induration $>10 \mathrm{~mm}$ after a Mantoux skin test. ${ }^{5}$ In Turkey, BCG is given in the first three months of life. The second, third, and fourth vaccines are given at 5-6 years, 11-12 years, and $16-17$ years, respectively. The prevalence of positive reactions was higher among children with BCG scars than among children without. Of course, we do not contend that the prevalence of infection with $M$ tuberculosis in these children is $31.3 \%$, because clearly distinguishing a tuberculin skin test reaction caused by infection with $M$ tuberculosis from a reaction caused by BCG vaccination is difficult. It is generally accepted that the larger the induration $(>10 \mathrm{~mm})$ the greater the likelihood that the reaction represents infection with $M$ tuberculosis and that tuberculin reactivity caused by BCG vaccination wanes after three to five years. For this reason and to avoid a boosting effect of the PPD test performed previously, the children included in the study had neither been given BCG nor a tuberculin skin test during the last five years.

Current recommendations suggest that tuberculin skin test results should be read 48-72 hours after administration. ${ }^{2}$ However, Howard and Solomon pointed out that strict adherence to these time limits often resulted in prolonged hospitalisation, delayed test placement, or patients interpreting their own test results. ${ }^{4}$ In a recent study that assessed the impact of tuberculin screening of all children during hospitalisation for acute medical care, of the 432 patients tested, only 304 were evaluable at 48 hours. The remaining 128 (30\%) children were discharged before a 48 hour evaluation. ${ }^{6}$

The positive predictive value of reading the Mantoux tuberculin skin test in healthy adults at 24 compared with 48 to 72 hours was reported to be $75 \%$ by Howard and Solomon. However, in children we found that the positive predictive value of any induration $(\geqslant 1 \mathrm{~mm})$ reading at 24 hours was relatively low (63\%) when a cut off of $\geqslant 10 \mathrm{~mm}$ was used to define a positive test. This rate increased to $86 \%$ if the size of the induration was $\geqslant 5 \mathrm{~mm}$ at 24 hours. On the other hand, in adolescents (aged 16-17 years) the positive predictive value of any induration reading at 24 hours was greater $(80 \%)$ than in adults $(75 \%)$. Also in children aged 6-7 and 11-12 years the negative predictive value of no induration reading at 24 hours was $98 \%$. Taken together, our results suggest that in the presence of $<5 \mathrm{~mm}$ tuberculin induration at 24 hours, it will not always be possible to tell whether this induration will develop into a positive test at 48 to 72 hours, but if there is no induration, especially in children younger than 13 years, it is highly possible (98\%) that infection has not occurred. However, the tests should still be evaluated at 48 to 72 hours for decisions in individual patients whenever possible.

1 Bilgiç H. Tüberküloz epidemiyolojisi. In: Kocabas A, ed. Tüberküloz kliniği ve kontrolu. Ankara, Turkey: Ajans Emel, Tüberküloz klinigi

2 Huebner RE, Schein MF, Bass JB. The tuberculin skin test. Clin lnfect Dis 1993;17:968-75.

3 Starke JR, Correa AG. Management of mycobacterial infection and disease in children. Pediatr Infect Dis $\mathcal{F}$ 1995;14: 455-70.

4 Howard TP, Solomon DA. Reading the tuberculin skin test. Who, when, and how? Arch Intern Med 1988;148:2457-9.

5 Ildirim İ, Hacimustafaoĝlu M, Ediz B. Correlation of tuberculin induration with thenumber of Bacillus CalmetteGuerin vaccines. Pediatr Infect Dis $\mathcal{F}$ 1995;14:1060-3.

6 Schutze GE, Rice TD, Starke JR. Routine tuberculin screening of children duringhospitalization. Pediatr Infect Dis f 1993;12:29-32. 